\title{
The Possibility of Air Express-Biotesting in the Process of Formaldehyde Removal from Air via Dielectric Barrier Discharge
}

\author{
A.G. Bubnov, S.A. Buymova* \\ Ivanovo State University of Chemistry and Technology \\ *Corresponding Author: byumova@mail.ru
}

Copyright (C) 2014 Horizon Research Publishing All rights reserved.

\begin{abstract}
The results of the adaptation of methods of water solutions biotesting for the assessment of air quality after the removal of formaldehyde from air via dielectric barrier discharge reactor are presented in this work. The conditions for the express-analysis of air are determined.
\end{abstract}

Keywords Air Cleaning, Biotesting, Dielectric Barrier Discharge

\section{Introduction}

Air pollution is a constant environmental problem in urban areas. Among the harmful substances contained in the atmosphere of cities, special attention should be paid to volatile organic compounds, particularly formaldehyde [1]. Currently new methods of such emissions neutralization are being developed. Thus, at the end of the last century, one of the most promising ways to solve this kind of environmental problems by removing organic contaminants from air was application of high-energy chemistry, in particular, the dielectric barrier discharge (DBD) [2] and [3]. It should be noted that the efficiency of using DBD to clean water via reactor with coaxially arranged electrodes (as in [4]), has been previously shown by numerous publications (eg, [5] and [6]) and validated in [7].

It is known that during the process of air cleaning from formaldehyde its oxidative destruction toxic by-products are formed in the reactor with DBD [2], and, therefore, an effective and informative method of quality control for air treated via DBD is necessary. With some limitations, biotests may present such method. There is every reason to believe that, improved and unified, these tests shall become pollution control instruments and allow to significantly reduce number of time-consuming and expensive analysis through chemical and instrumental methods [8]. Today, biotests for the determination of toxicity in natural water, waste water, and soil, as well as of hazardous waste classes has been elaborated. Moreover, this work shows how biotests can be used in real life to control the performance efficiency of plasma-chemical device described in [4] which is used for cleaning water from organic pollutants. With appropriate justification biotests allow to evaluate the sample being studied directly by the reaction of living organisms. However, currently there are no normative methods of express testing for air quality control (which would stipulate/provide test execution conditions) [8].Therefore, the newly developed methods of biotesting for air cleaning quality control can allow to assess the total biological toxicity of purified air. In addition, it will be possible to comprehensively assess the toxicity of air if it contains two or more pollutants. In connection with this, the development of express analysis for air quality monitoring is of great current importance. Therefore, the aim of this work is to determine the possibility of adapting the existing biotesting methods for air quality monitoring through the example of air cleaning of formaldehyde in the reactor with DBR.

\section{Methodology}

DBD was excited by high-voltage AC transformer of industrial frequency $50 \mathrm{~Hz}$. Electrodes' voltage was $12 \mathrm{kV}$. Discharge current was $230 \mathrm{~mA}$, i.e. specific power of discharge was approximately $106 \mathrm{~mW} / \mathrm{cm}^{3}$. It is exactly under these conditions, as shown in [3], that there is the maximum degree of formaldehyde removal from air (at least $95 \%$ ). And further increase of voltage is not advisable, since the degree of formaldehyde removal does not change anymore. The discharge was excited 20 minutes after the initial and steady0state concentration of formaldehyde was set into the discharge device. Air consumption was $2 \mathrm{~cm}^{3} / \mathrm{s}$ (corresponding to a contact time of 13,6 seconds).

The following methods of control of gas phase composition and degradation products of formaldehyde in the DBR (gaseous and liquid phases) were used:

Photo-colorimetric standard methods (NO, $\mathrm{NO}_{2}$, 
formaldehyde, $\mathrm{NO}_{2}-, \mathrm{NO}_{3}$-);

Iodometric and absorption spectroscopy $\left(\mathrm{O}_{3}\right)$;

Titrimetric $\left(\mathrm{CO}\right.$ and $\left.\mathrm{CO}_{2}\right)$.

In this works as test-organisms (biotests), we used test-culture of Chlorella Vulgaris Beijer (alga Chlorella), Daphnia Magna (crustacean Daphnia) and Poecillia Reticulata Peters (freshwater aquarium fish guppy).

Biotesting method of the algae Chlorella is based on the registration of differences in optical density of the test-culture grown in non-toxic environment (control) and test samples of water (experience), in which these materials may be present. Measurement of the algal suspension optical density allowed to efficiently control the change in the number of cells in the control and experimental variants of acute toxicological experiment, conducted in a specialized multi-cuvette cultivator. For biotesting we used pure culture of Chlorella Vulgaris Beijer, maintained in exponential growth phase (one day after reseeding in cultivator). To maintain the exponential growth phase of algae reseeding was carried out daily. Water toxicity criteria is a decrease of $20 \%$ or more (growth inhibition) or an increase of $30 \%$ or more (stimulation of growth) of the optical density of the culture grown during 22 hours in the tested water, compared to its growth in control environment prepared using distilled water.

Biotesting method using Daphnia Magna is based on establishing the difference between the number of biotests died in the sample being analyzed (experience) and in the water used for cultivation (control). In each experiment, at certain time intervals the number of survived test-organisms was counted. Then the average number of survived biotests was determined and the percentage of death in the experiment comparing to the control group was calculated

The criterion of the acute lethal toxicity is the death of $50 \%$ and more of Daphnia Magna during 96 hours-biotesting. The following operations were performed during biotesting:

Water sample was placed in a $100 \mathrm{ml}$ glass vessel (experience), other vessels were filled with the same volume of filtered water from the tanks, where daphnia have been cultivated (control); experiment and control were repeated three times;

10 -24-hour age daphnia were placed in each test and control vessel, they were quickly transferred by means of a glass tube with a diameter of $5-7 \mathrm{~mm}$, submerging it in water;

Biotesting duration was 96 hours, and during the biotesting daphnia were not fed;

At the intervals of $1,6,24,48,72$, and 96 hours of biotesting living daphnia were visually counted. Daphnia were considered living if they moved freely in the water, or came up from the bottom of the vessel not later than 15 seconds after the vessel had been a little shaken (other daphnia were considered dead).

Biotesting results are considered reliable if the death of daphnia of the control group does not exceed $10 \%$ during the whole observation period.
Biotesting method using Poecilia Reticulata Peters is based on the difference between the number of biotests died in the sample being analyzed (experience) and in the water that does not contain toxic substances(control). The criterion of the acute lethal toxicity is the death of $50 \%$ or more fish in the experiment as compared with the control during the 96 hours-biotesting. Up to 2 day old ( 24 through 48 hours) fingerlings of guppies were used as test organisms. The prepared water samples of $100 \mathrm{ml}$ were poured in glass vessels (experience). Other vessels were filled in the same manner with dechlorinated drinking water(control). Ten 24 - 48 hours old guppies were placed in each of the experimental and control vessels. Duration of biotesting was 96 hours. During the biotesting fish were not fed. Every day the survived items were counted and the dead ones were removed. Guppies were considered dead if they did not give any signs of movement or breathing when touched by a glass stick. The results were taken into account, if during the biotesting the concentration of dissolved oxygen was not less than $4 \mathrm{mg} / \mathrm{l}$, and the temperature was $25 \pm 1{ }^{\circ} \mathrm{C}$.

Random errors of all measurements were calculated by the method of Student.

Furthermore, biotesting using daphnia and guppy was conducted under different conditions (the amount of the absorbent $(100 \mathrm{~mL})$, air flow rate $2 \mathrm{~cm}^{3} / \mathrm{s}$, samples selection time 15 minutes, termolyuminostate tempreture maintained at $20{ }^{\circ} \mathrm{C}$, illuminance $500-1000$ lux, during Biotesting sample was not aerated):

After samples selection, daphnia (or guppy) have been transferring into water during 30 minutes, then the sample was placed into the termolyuminostat, during 96 hours $10 \mathrm{ml}$ of water has evaporated;

Daphnia (or guppy) have been transferring into water before samples selection; after samples selection the sample was placed in the termolyuminostat, during 96 hours $10 \mathrm{ml}$ of water has evaporated;

Daphnia was placed in a plastic cup with a sealed cover; after samples selection, it was placed in the termolyuminostat. During 96 hours water has not evaporated.

\section{Results and Discussion}

In order to identify the conditions and determine the acceptability of the application and use of biotesting methods (developed for determining the toxicity of hazardous waste water extracts) for the air quality control after it has been processed in the DBD, first it was necessary to select the conditions for an adequate definition of the toxicity of water sample containing air. For this, we aspirated air contaminated with formaldehyde through the vessel with water (water volume was $100 \mathrm{ml}$, sample selection time -15 min) and measured the concentration of formaldehyde in water. The total volume of water in absorption vessels was determined in accordance with biotesting method recommendations. Except that the amount of water was not 
$100 \mathrm{ml}$, but $50 \mathrm{ml}$ (i.e., we selected a sample bubbling air successively through two vessel with capacity of $50 \mathrm{ml}$, then poured samples together and then a single sample of $100 \mathrm{ml}$ was tested. Samples selection time was chosen on the basis of the data obtained earlier (Fig. 1) as by this time the concentration of formaldehyde absorbed by the water in absorption vessel reaches maximum air flow 1 to $4 \mathrm{~cm}^{3} / \mathrm{s}$. It should be noted that the maximum permissible concentration of formaldehyde in water of fisheries (PDKr.h) $-0,1 \mathrm{mg} / 1$. Table 1 shows that nearly the same concentration $(0,11 \mathrm{mg} / \mathrm{l})$ is created in the vessel during the selection of air with the speed of $2 \mathrm{~cm}^{3} / \mathrm{s}$ and $100 \mathrm{ml}$ volume of water for sample selection in the single absorption vessel. Therefore, this sample should be toxic to the test-organisms.

Table 1. The concentration of formaldehyde depending on the flow of air

\begin{tabular}{|c|c|c|c|}
\hline \multirow{2}{*}{$\begin{array}{c}\text { Air } \\
\text { consumption } \\
\mathrm{cm} 3 / \mathrm{s}\end{array}$} & \multirow[t]{2}{*}{$\begin{array}{l}\text { The concentration } \\
\text { of formaldehyde } \\
\text { in air, } \mathrm{mg} / \mathrm{m} 3\end{array}$} & \multicolumn{2}{|c|}{$\begin{array}{l}\text { The concentration of } \\
\text { formaldehyde in water } \\
\text { absorption vessels for various } \\
\text { volumes of sample, } \mathrm{mg} / \mathrm{l}\end{array}$} \\
\hline & & $\begin{array}{l}1 \text { sample } \\
\text { of } 100 \mathrm{ml}\end{array}$ & $\begin{array}{c}2 \text { samples } \\
\text { of } 50 \mathrm{ml}\end{array}$ \\
\hline 1,4 & 4,58 & 0,057 & 0,12 \\
\hline 2 & 6,15 & 0,11 & 0,22 \\
\hline 2,7 & 8,85 & 0,22 & 0,43 \\
\hline 3,7 & 11,52 & 0,38 & 0,77 \\
\hline
\end{tabular}

The next stage was checking the toxicity of selected water using chlorella, daphnia and guppies. The results of these experiments are shown in Fig. 1 - 3 .

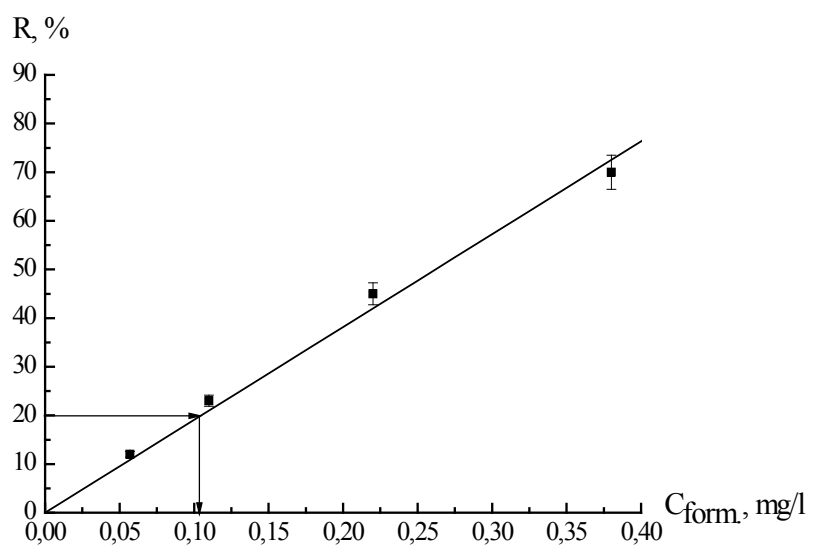

Figure 1. Reduction of number of Chlorella Vulgaris Beijer (R) in different concentrations of formaldehyde $\left(\mathrm{C}_{\text {form }}\right)$ in water

The experiment results show that (Fig. 1) the inhibition of test-culture growth by $20 \%$ happens at the concentration of formaldehyde of $0.1 \mathrm{mg} / \mathrm{l}$ (the concentration of formaldehyde in air is $5,26 \mathrm{mg} / \mathrm{m}^{3}$, i.e. exceeds the PDK 150 times). The experiment showed that the test-culture of Chlorella Vulgaris Beijer was sensitive to sample composition.

As in the case of chlorella, before biotesting of samples of contaminated air, we first tested the toxicity of selected water using daphnia at concentrations shown in Table. 1 (see Fig. 2).

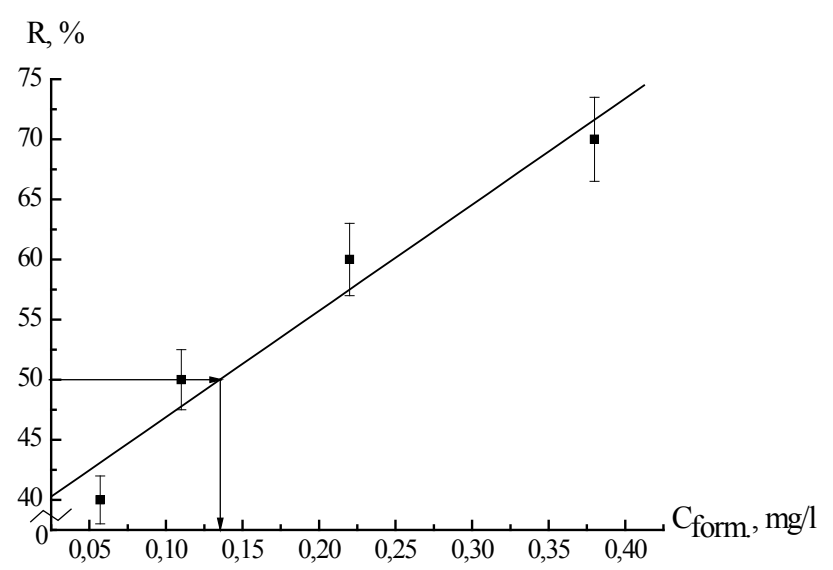

Figure 2. Reduction of number of Daphnia Magna (R) at different concentrations of formaldehyde $\left(\mathrm{C}_{\text {form. }}\right)$ in water

Figure 2 shows that during 96 hours $50 \%$ of daphnia die under formaldehyde concentration of $0,13 \mathrm{mg} / \mathrm{l}$.

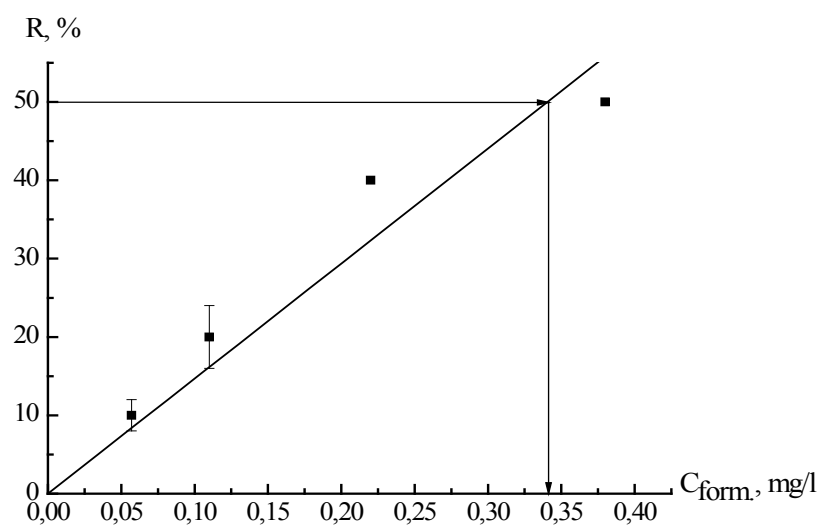

Figure 3. Reduction of number of Poecillia Reticulata Peters(R)at different concentrations of formaldehyde $\left(\mathrm{C}_{\text {form }}\right)$ in water

Fig. 3 shows that during 96 hours $50 \%$ of guppy die under formaldehyde concentration equal to $0,34 \mathrm{mg} / \mathrm{l}$. At the same time, the test objects such as chlorella and daphnia are sensitive to the samples, in which the concentration of formaldehyde is equal to the $\mathrm{PDK}_{\text {r.h. }}$. It can be concluded that the guppies are not sensitive to the composition of this sample. However, as further biotesting procedure was carried out using samples contaminated by secondary products of oxidative degradation of formaldehyde in the DBD, it made sense to carry out experiments under the same conditions as the other biotest. Moreover, as shown below, the sensitivity of test-organisms, including guppy, can be assessed using universal indicator of potential toxicity(PT) which can be calculated for impurities in the air, as in [6] using the formula:

$$
P T=\sum_{i}^{n}\left(C_{i} / P D K_{i}\right),
$$


$\mathrm{C}_{\mathrm{i}}$ - concentration of the pollutant in the air, $\mathrm{mg} / \mathrm{m}^{3}$; PDK - maximum allowable single concentration of the pollutant in the air of populated areas, $\mathrm{mg} / \mathrm{m}^{3}$.

To identify the acceptability of the adapted biotesting method for monitoring air quality after its purification from formaldehyde in the DBD reactor, the biotesting of several types of samples was performed:

1. Unpolluted air, after passing through the reactor (without discharge excitation).

2. Mixture of air and formaldehyde passed through the reactor without DBD excitation.

3. Air after its treatment in DBD.

4. Mixture of air and formaldehyde treated in DBD.

5. Mixture of air and formaldehyde after processing in the DBD that passed through the absorbing cartridge with the GTT catalyst (the effectiveness of its use for suppressing ozone has been shown in many works, for example [9]). The catalyst for ozone decomposition has been industrially tested and put into production [9]. During the experiments the catalyst was placed behind the DBR area (in the area of the afterglow), but first it was sieved (pellets size of $0,315 \mathrm{~mm}$ or less), and calcined in air at $300{ }^{\circ} \mathrm{C}$ for at least 2 hours. Weight of catalyst placed in the absorption glass cartridge, of an inner diameter of $\varnothing 5$, and $2 \mathrm{~cm}$ long, was about $2 \mathrm{~g}$. For the chemical composition of the catalyst, the GTT (\% mass) - see [9]. We did not conduct the biotesting of mixture of air and formaldehyde passed through the reactor without DBR excitation with GTT catalyst, since it is known, that the catalyst placed behind the DBR area does not affect the concentration of organic substances removed (formaldehyde), i.e. the sample is similar to the sample number 3 "mixture of air and formaldehyde, passed through the reactor without DBR excitation".

Summary table of the results of the solutions toxicity evaluation during the biotesting using Chlorella Vulgaris Beijer, Daphnia Magna and Poecillia Reticulata Petersare shown in Tables. $2-4$.

Table 2. The results of biotesting using chlorella

\begin{tabular}{|c|c|c|c|c|c|c|c|}
\hline \multirow{2}{*}{ Sample No. } & \multicolumn{5}{|c|}{ The concentrations of substances, $\mathrm{mg} / \mathrm{m}^{3}$} & \multirow{2}{*}{ PT } & \multirow{2}{*}{$\mathrm{R}, \%$} \\
\cline { 2 - 8 } & $\mathrm{O}_{3}$ & $\mathrm{CH}_{2} \mathrm{O}$ & $\mathrm{NO}_{2}$ & $\mathrm{CO}$ & $\mathrm{NO}$ & & 10 \\
\hline 1 & - & - & - & - & - & - & 166 \\
\hline 2 & - & 5,8 & - & - & - & 10642 & 65 \\
\hline 3 & 1701 & - & 2 & - & 0,3 & 113356 & 87 \\
\hline 4 & 1810 & 0,2 & 2,7 & 1,2 & 1,5 & 21 & 15 \\
\hline 5 & - & 0,2 & 1,22 & - & 0,23 & 21 & 15 \\
\hline
\end{tabular}

Results of biotesting (Tables $2-4$ ) show that the percentage of the reduction of biotests number in the sample 5 was $15 \%$ or less, it proves that after the air has been cleaned in DBD, the samples were not toxic to the test-cultures.

Table 3. The results of biotesting using daphnia

\begin{tabular}{|c|c|c|c|c|c|c|c|}
\hline \multirow{2}{*}{ Sample No. } & \multirow{2}{*}{$\mathrm{PT}$} & \multicolumn{2}{|c|}{ Conditions a. } & \multicolumn{2}{c|}{ Conditions $\mathrm{b}$} & \multicolumn{3}{c|}{ Conditions c. } \\
\cline { 3 - 8 } & & $\mathrm{R}, \%$ & $\mathrm{LT}_{50}, \mathrm{~h}$ & $\mathrm{R}, \%$ & $\mathrm{LT}_{50}, \mathrm{~h}$ & $\mathrm{R}, \%$ & $\mathrm{LT}_{50}, \mathrm{~h}$ \\
\hline 1 & - & 10 & - & 10 & - & 10 & - \\
\hline 2 & 166 & 30 & - & 60 & 100 & 50 & 102 \\
\hline 3 & 10658 & 70 & 72 & 50 & 82 & 60 & 76 \\
\hline 4 & 11354 & 50 & 84 & 90 & 45 & 80 & 56 \\
\hline 5 & 21 & 10 & - & 10 & - & 10 & - \\
\hline
\end{tabular}

Table 4. The results of biotesting using guppies

\begin{tabular}{|c|c|c|c|c|c|c|c|}
\hline \multirow{2}{*}{ Sample No. } & \multirow{2}{*}{$\mathrm{PT}$} & \multicolumn{2}{|c|}{ Conditions a. } & \multicolumn{2}{c|}{ Conditions $\mathrm{b}}$. & \multicolumn{2}{c|}{ Conditions c. } \\
\cline { 3 - 8 } & & $\mathrm{R}, \%$ & $\mathrm{LT}_{50}, \mathrm{~h}$ & $\mathrm{R}, \%$ & $\mathrm{LT}_{50}, \mathrm{~h}$ & $\mathrm{R}, \%$ & $\mathrm{LT}_{50}, \mathrm{~h}$ \\
\hline 1 & - & 0 & - & 40 & - & 0 & - \\
\hline 2 & 166 & 20 & - & 30 & - & 30 & - \\
\hline 3 & 10658 & 50 & 84 & 50 & 84 & 50 & 90 \\
\hline 4 & 11354 & 60 & 62 & 70 & 58 & 60 & 62 \\
\hline 5 & 21 & 10 & - & 10 & - & 10 & - \\
\hline
\end{tabular}


Summary of biotesting results are shown in Table. 5 .

Table 5. The results of air samples biotesting

\begin{tabular}{|c|c|c|c|c|c|c|c|c|c|}
\hline \multirow{2}{*}{ Sample No. } & \multicolumn{5}{|c|}{ The concentrations of substances, $\mathrm{mg} / \mathrm{m}^{3}$} & \multirow{2}{*}{ PT } & \multirow{2}{*}{$\begin{array}{c}\text { Chlorella } \\
\text { R, \% }\end{array}$} & \multirow{2}{*}{$\begin{array}{c}\text { Daphnia, } \\
\mathrm{LT}_{50}, \mathrm{~h}\end{array}$} & \multirow{2}{*}{$\begin{array}{l}\text { Guppies, } \\
\mathrm{LT}_{50}, \mathrm{~h}\end{array}$} \\
\hline & $\mathrm{O}_{3}$ & $\mathrm{CH}_{2} \mathrm{O}$ & $\mathrm{NO}_{2}$ & $\mathrm{CO}$ & NO & & & & \\
\hline 1 & - & - & - & - & - & - & 10 & - & - \\
\hline 2 & - & 5,8 & - & - & - & 166 & 45 & 102 & - \\
\hline 3 & 1701 & - & 2 & - & 0,3 & 10658 & 65 & 76 & 90 \\
\hline 4 & 1810 & 0,2 & 2,7 & 1,2 & 1,5 & 11354 & 87 & 56 & 62 \\
\hline 5 & - & 0,2 & 1,22 & - & 0,23 & 21 & 15 & - & - \\
\hline
\end{tabular}

It should be noted that the results of biotesting using Daphnia Magna under the conditions (a) show that the lethal time $\mathrm{LT}_{50}$ value is greater than the value obtained under the conditions(b)and(c).Therefore, we can conclude that the time of placing test-organisms in a sample affects the results of biotesting. Furthermore, there is a lethal time dependence of the value of PT, and in the course of the experiments under the conditions(a)and(b)the evaporation of water in the amount of $10 \mathrm{ml}$ was observed.

On the grounds of The results of the experiments (taking into account the data of the tab. $2-5$ ) we can formulate the basic requirements for the performance of biotesting and the monitoring of effectiveness of cleaning air from formaldehyde using DBD with the studied test-organisms.

The volume of absorbent should be $100 \mathrm{ml}$, air flow $2 \mathrm{~cm}^{3} / \mathrm{s}$, time of samples selection $-15 \mathrm{~min}$. daphnia and guppies should be placed before the selection in a plastic cup with a sealed lid. The selected sample should be placed in termolyuminostat with the temperature maintained at $20{ }^{\circ} \mathrm{C}$ (for Daphnia Magna) and $25{ }^{\circ} \mathrm{C}$ for Poecillia Reticulata Peters. The illumination should be $500-1000$ lux, during biotesting the sample should not be aerated, and the biotests should not be fed.

The concentration of contaminants in the sample increases, and that increase leads to a decrease in the value of lethal time $\mathrm{LT}_{50}$ for Daphnia Magna biotests. The experimental conditions (c) exclude changes in the concentration of pollutants as a result of evaporation. The value of the lethal time $\mathrm{LT}_{50}$ takes the average of the indicators of lethal time $\mathrm{LT}_{50}$ for the conditions (a) and (b).The results of biological testing of air samples using Poecillia Reticulata Peters show that the value of the lethal time $\mathrm{LT}_{50}$ is not dependent of the time of test-organisms placement in the sample, nor of the leak tightness of the vessel in which the experiment is conducted. In the course of study, the optimum conditions of the biotesting using Daphnia Magna test organisms are conditions (c). Conditions of biotesting of air samples using Poecillia Reticulata Peters need to be improved.

\section{Conclusion}

[6] Bubnov A.G., BurovaE.Yu., Grinevich V.I., Rybkin V.V.,
Kim J.-K., Choi H.-S.Plasma-catalytic decomposition of

[6] Bubnov A.G., BurovaE.Yu., Grinevich V.I., Rybkin V.V.,
Kim J.-K., Choi H.-S.Plasma-catalytic decomposition of

This paper shows the possibility of performing biotesting using daphnia and chlorella test-organisms for air quality control after it has been cleaned from formaldehyde in the reactor with a dielectric barrier discharge. Additional conditions relating to the selection of samples for biotesting are determined. These conditions allow to control in accordance with the requirements for this type of analysis. Chlorella Vulgarism Beijer and Daphnia Magna were sensitive to the sample composition. Biotests Poecillia Reticulata Peters were sensitive to the samples, which PT was equal to the 330 or more, while the test organisms daphnia and chlorella were sensitive to the composition of samples, which PT was equal to 166 or more. The lowest value of $\mathrm{LT}_{50}$ for Daphnia Magna corresponds to the greatest potential toxicity of the sample and the highest percentage of Chlorella Vulgaris Beijer population reduction (they are much easier to grow in the laboratory conditions and get enough material for research).

\section{REFERENCES} Introduction to Indoor Air Quality (IAQ).Formaldehyde).

[2] Storch D.M., Kushner M.J. Destruction mechanisms for formaldehyde in atmospheric pressure low temperature plasmas // J. Appl. Phys. 1993. V. 73. № 1. P. 51-55.

[3] Bubnov A.G., Grinevich V.I., Aleksandrova S.N., Kostrov V.V. Polymerization of phenol. Vapor in a barrier-discharge plasma // High Energy Chemistry. 1997. № 31. P. 264 - 267.

[4] Bubnov A.G., Grinevich V.I., Maslova O.N., Rybkin V.V.Application of barrier discharge to the treatment of water from phenol: reactor thermal characteristics // Theoretical Foundations of Chemical Engineering. 2007. V. 41. № 4. P. 396 - 400.

[5] Bubnov A.G., Grinevich V.I., Kuvykin N.A., Maslova O.N.The kinetics of plasma-induced degradation of organic pollutants in sewage water// High Energy Chemistry. 2004. V. 38. № 1. P. $41-45$.
[1] URL:http://www.epa.gov/iaq/formaldehyde.html 
phenols in atmospheric pressure dielectric barrier discharge // Plasma Chemistry and Plasma Processing. 2006. V. 26. № 1. P. $19-30$.

[7] Bubnov A.G., BurovaE.Yu., Grinevich V.I., Rybkin V.V., Kim J.-K., Choi H.-S.Comparative actions of NIO and TIO2 catalysts on the destruction of phenol and its derivatives in a dielectric barrier discharge // Plasma Chemistry and Plasma Processing. 2007. V. 27. № 2. P. 177-187.
[8] Batzias, F.,Siontorou C.G.A novel system for environmental monitoring through acooperative/synergistic scheme between bioindicators and biosensors //Journal ofEnvironmental Management. 2007. № 82. P. 221-239.

[9] Chumadova E.S., Kostrov V.V., Grinevich V.I.Oxidation of carbon monoxide and methane in air medium in barrier discharge plasma // Russian Journal of Applied Chemistry. 2000. V. 73. № 5. P. 775-778. 